\title{
Quadrat I+II: a peça serial de Samuel Beckett
}

Resumo: $O$ artigo aborda a peça para televisão Quadrat I+II, dirigida por Samuel Beckett para a Süddeutscher Rundfunk (SDR) em Stuttgart, como um modelo de peça serial. Os procedimentos serialistas da peça são discutidos no contexto de uma problematização da organização narrativa e dramát ica do tempo, algo que Beckett realiza em suas demais obras, mas assume contornos específicos no caso de uma peça para a televisão. Nesse contexto, as condições de produção da peça também são levadas em consideração.

Palavras-chave: Samuel Beckett, peça para televisão, serialismo.

Abstract. The article focuses on the television play Quadrat I II, directed by Samuel Beckett for the Süddeutscher Rundfunk (SDR) in Stuttgart, as a model of serial play. The serialist procedures of the play are discussed in the context of a problematization of the narrative and dramatic organization of the time, which Beckett accomplishes in his other works, but assumes specific contours in the case of a television play. In this context, the production conditions of the play are considered.

Key-words: Samuel Beckett, television play, serialism.

\section{Produção}

Em 30 de janeiro de 1980, Beckett envia a Reinhart Müller-Freienfels, diretor artístico da Süddeutscher Rundfunk (SDR) em Stuttgart, duas páginas contendo "a crazy 
invention for TV". A invenção em questão era Quad uma peça para quatro atores e percussão, constituída apenas de movimentos seriais sobre um quadrado, sem recurso algum à palavra. Experimento ousado mesmo no âmbito da obra tardia de Beckett, a peça retoma muitos aspectos de trabalhos anteriores. Como indica James Knowlson em sua biografia de Beckett:

essa peça sem palavras para quatro dançarinos se desenvolveu naturalmente do interesse de Beckett pelo movimento coreográfico e de sua desconfiança radical da linguagem. Ele manifestou ao cameraman da SDR, Jim Lewis, a dificuldade que ele então tinha em escrever sem ter a impressão intensa de que as palavras inevitavelmente seriam ment iras. Seu fascínio pela imagem visual e seu interesse em estruturas musicais tomaram conta da escrita dramática que em princípio dependia da linguagem. A imagem sempre tinha sido importante nas peças de Beckett. Agora, em suas últimas peças para o palco e para a televisão, ela era soberana (KNOWLSON, 1996, p. 591).

Dificilmente Beckett consideraria viável produzi-la caso ela não fosse antecedida por experiências muito bem sucedidas com a equipe de Müller-Freienfels. Desde a primeira colaboração em 1966, para a realização de Eh Joe, as portas da SDR tinham ficado abertas para ele e cada despedida ao fim de um trabalho vinha acompanhada pela expectativa de que um dia ele retornaria com uma nova peça. ${ }^{1} \mathrm{O}$ orçamento folgado, a possibilidade de dar a últ ima palavra e a disponibilidade de uma equipe extremamente bem preparada criaram as condições para duas décadas de trabalho conjunto, do qual resultaram diversas peças concebidas especialmente para a produção em Stuttgart.

De maneira geral, o que tornou possível a produção e a transmissão de peças como as de Beckett, as quais eram vistas no fim da noite por cerca de 300 mil telespectadores, são condições de produção muito especiais. O sistema público da televisão alemã até meados dos anos 1980 permitia pensar a televisão como um aparato técnico e cultural sujeito ao controle e à influência de tendências sociais diversas. Desde sua implantação no pós-guerra, ele se organizava segundo diretrizes de uma política cultural social-democrata que

1 Um registro insubstituível dessa colaboração é dado por um texto do próprio Müller-Freienfells, em que ele relembra as diversas passagens de Beckett pelos estúdios da SDR. Cf. MÜLLER-FREIENFELS, 1996. Sobre a produção de Quadrat I+II, ver também o texto de Konrad Körte (KÖRTE, 2011), engenheiro de som da SDR, e os trechos da biografia de Knowlson a respeito do trabalho de Beckett em Stuttgart. 
defendia o novo meio técnico como uma forma politicamente independente de esclarecimento e formação cultural no pós-guerra europeu. Mesmo nesse contexto, a produção de Stuttgart era singular. Nos estúdios da SDR, desenvolveu-se a partir dos anos 1950 o que ficou conhecido como o "estilo de Stuttgart". Reunindo uma equipe que trabalhou conjuntamente durante anos com boas condições técnicas e financeiras, a produção de Stuttgart talvez fosse a mais ambiciosa no panorama dos filmes televisivos alemães daquela época. Ainda que formatos convencionais e padronizações sejam a tônica no âmbito de um modo industrial de produção, como é o caso da televisão, na SDR tentavase pensar a narrativa televisiva como um gênero autônomo e procurava-se levar o filme para além dos padrões narrativos convencionalizados. Nos anos 1950, quando as condições técnicas favoreciam a concepção do filme como uma peça de câmera, a ênfase na cenografia anti-ilusionista, com a mera sugestão de espaços e a concentração da câmera nos rostos dos atores tornou-se um modelo para o aproveitamento dos limites restritos da tela do monitor. Peças de Beckett como Eh Joe e Trio-Fantasma retomam, sem compromisso realista, elementos dessa tendência. Posteriormente, com a invenção do videotape e a colaboração da câmera eletrônica com a câmera de cinema, a equipe da SDR desenvolveu uma tradição de filmes e documentários que trouxeram a história contemporânea e a investigação de questões sociais para o interior do filme televisivo. Embora as peças de Beckett sejam casos singulares mesmo no interior dessa estrutura sofisticada, trabalhos de autor no interior da produção industrial, não há como negar que ele não só se beneficiou da estrutura desse meio de produção como contribuiu para desenvolvê-la. ${ }^{2}$

Ciente dessas condições, Beckett continua na mesma carta a Müller-Freienfels citada acima: "Exceto pela estrutura básica, a peça está aberta à discussão em todos os seus aspectos: luz, cor, figurino, tipos de instrumentos de percussão, tempo etc. Uma empreitada coletiva, se é que já houve alguma" (FEHSENFELD et al., 2016, p. 522). A menção ao caráter colet ivo do trabalho não era somente um sinal de confiança mútua e de boas condições de produção. Ela também evidencia que Beckett sabia muito bem que não tinha como antecipar na escrita a decisão a respeito de um conjunto de elementos imprescindíveis à viabilização da peça. Se é verdade que a dramaturgia de Beckett torna-se

Para uma discussão abrangente e muito bem informada da implantação da televisão alemã no pós-guerra e do filme televisivo como gênero, em particular na SDR, cf. HICKETHIER, 1980. 
cada vez mais minuciosa e rubricada com a experiência de direção, de modo que a cena já vinha prefigurada no palco imaginário da escrita, também é necessário observar que os ensaios também eram ocasiões para reformulação do texto a part ir das exigências materiais da cena. ${ }^{3}$

A "estrutura básica" foi provavelmente o que, à primeira vista, passou a MüllerFreienfels a impressão de tratar-se de uma "partida de xadrez" (MÜLLER-FREIENFELS, 1998, p. 415): o diagrama de um quadrado, seguido da indicação de quatro percursos pelos vértices $(A, B, C, D)$ e pelo ponto central $(E)$, a serem realizados em quatro séries dist intas por quatro figuras - atores, dançarinos ou mímicos - cobertos da cabeça aos pés pelo mesmo figurino em cores distintas (branco, amarelo, vermelho e azul). As figuras entram uma depois da outra, realizam seu percurso pelo quadrado a partir de seu vértice de entrada e, quando todas já estão presentes, saem na ordem em que entraram. Inicia-se então uma nova série a partir das últ ima figura.

The players $(1,2,3,4)$ pace the given area, each following his part icular course. Area: square.

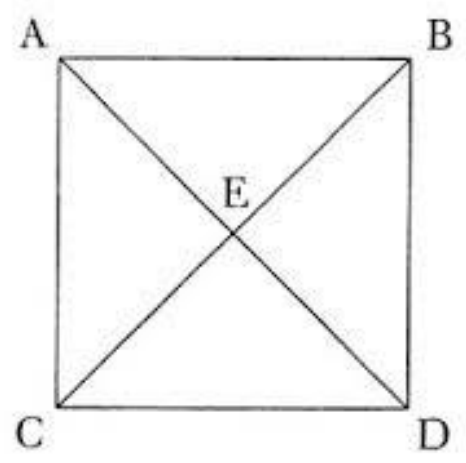

Length of side: 6 paces.

Course 1: $A C, C B, B A, A D, D B, B C, C D, D A$

Course 2: $B A, A D, D B, B C, C D, D A, A C, C B$

Course 3: $C D, D A, A C, C B, B A, A D, D B, B C$

Course 4: $D B, B C, C D, D A, A C, C B, B A, A D$

3 Cf. a encenação de Fim de Partida em Berlim, em 1967 e meu artigo a respeito (GATTI, 2014b). 
1 enters at A, completes his course and is joined by 3. Together they complete their courses and are joined by 4 . Together all three complete their courses and are joined by 2 . Together all four complete their courses. Exit 1. 2, 3 and 4 cont inue and complete their courses. Exit 3. 2 and 4 cont inue and complete their courses. Exit 4. End of 1st series. 2 cont inues, opening 2nd series, completes his course and is joined by 1. Etc. Unbroken movement.

1st series (as above): 1, 13, 134, 1342, 342, 42

2nd series: 2, 21, 214, 2143, 143, 43

3rd series: 3, 32, 321, 3214, 214, 14

4th series: $4,43,432,4321,321,21$

Four possible solos all given.

Six possible duos all given (two twice).

Four possible trios all given twice.

Without interruption begin repeat and fade out on 1 pacing alone (BECKETT, 1986, p. 4512).

Diferentemente do detalhamento rigoroso das séries, as demais indicações de cena tinham um caráter um tanto hipotético, como se não passassem de sugestões do autor à produção. De modo geral, os demais elementos são pensados como desdobramentos do serialismo da estrutura básica: uma sistemática multiplicação por quatro de cada aspecto envolvido na peça. Cada figura seria acompanhada por um percussionista (o texto sugere: tambor, gongo, triângulo e bloco de madeira) localizado na penumbra ao fundo da cena. A percussão, contudo, deveria ser intermitente, de modo que, ocasionalmente, apenas os passos das figuras fossem ouvidos. O mesmo sistema valeria também para as cores dos focos de luz, que repetiriam as cores dos figurinos: branco, amarelo, vermelho e azul. Renunciando aos tons de cinza das peças anteriores, cada figura seria iluminada por um foco de luz de cor distinta, que acompanhariam seus movimentos pelo quadrado. 0 figurinos deveriam ser de corte idêntico e as figuras tão semelhantes entre si quanto possível, sendo a diferença de gênero irrelevante. A peça seria filmada com uma câmera fixa e elevada, de modo a enquadrar tanto atores quanto músicos e transcorrer num ritmo lento, um passo por segundo, beirando os 25 minutos. 
Após uma conversa preliminar em Paris no início de 1981 com o câmera Jim Lewis, Beckett chegou a Stuttgart em 13 de abril de 1981, dia de seu aniversário, para trabalhar na pré-produção da peça. O depoimento de Konrad Körte, engenheiro de som da equipe da SDR, explicita o quanto as circunstâncias de produção exigiram de Beckett alterações das indicações de cena inicialmente previstas para transpor o mecanismo das séries em imagem televisiva. De acordo com seu relato, essa primeira visita resumiu-se ao enfrentamento de um conjunto de dificuldades. Para a escolha da percussão foi necessária a metade de uma tarde na sala de instrumentos da orquestra sinfônica da rádio da SDR, pois Beckett queria quatro instrumentos que soassem sem brilho e ressonância, de modo abafado e monótono (KÖRTE, 2011, p. 287). O percussionista da orquestra sugeriu um instrumento de madeira (tambor de fenda), um de metal (gongo) e um de pele (tambor africano), mas o quarto instrumento só foi definido com a sugestão do próprio Körte de utilizar a base de papelão de cesta de papéis. Os egressos de uma escola de balé, por sua vez, que haviam sido chamados para fazerem as quatro figuras, apesar de conseguirem executar a sequência de passos prevista, pareceram a Beckett mecânicos demais, incapazes de apresentar pelo passo e pela postura o que Müller-Freienfels definiu de "monotonia febril". A colaboração dos músicos para esse efeito também se mostrou difícil, pois Beckett queria que eles, além de acompanharem os dançarinos, também contribuíssem com improvisações. A fim de que o esforço do movimento fosse visível, sugeriu-se a instalação de dois grandes vent iladores, contra os quais os dançarinos se movimentariam. Como as máquinas eram barulhentas, os músicos teriam que permanecer isolados numa cabine, o que exigiria que o som da percussão fosse transmit ido à cena por meio de auto-falantes. Além dessas dificuldades, as primeiras provas da tomada de som mostraram as dificuldades de alternar a percussão com um ritmo de base produzido pelos passos, pois esses eram irregulares ou inaudíveis. A fixação de uma espécie de lixa na sola dos sapatos dos dançarinos, de modo a produzir o chiado característico, acabou produzindo por outro lado um ritmo de base ainda mais marcante que o da percussão, mas que era enfraquecido pelo ruído das roupas dos atores. $O$ problema maior foi, contudo, o da iluminação, pois os focos de luz colorida tendiam a se confundir em uma luz indefinida quando os dançarinos se aproximavam uns dos outros, no centro do quadrado.

Müller-Freienfells recorda que depois de dois dias de ensaios, a equipe estava exausta e Beckett se sentia derrotado porque muito do que ele havia concebido em sua 
escrivaninha não funcionava na prática. De volta a Paris, ele escreveu a Müller-Freienfels que desistiria do projeto, pois a peça não tinha como ser realizada tal como concebida (FEHSENFELD et al, 2016, p. 547-8). A produção poderia ser levada adiante com as modificações sugeridas na fase de pré-produção, mas ele não se sentia mais capaz de dirigi-la. A um amigo ele escreveu: "Os dias em Stuttgart não foram muito sat isfatórios. Estou bem perdido nas tecnicidades da TV e não devo nunca mais voltar a escrever para esse meio" (FEHSENFELD et al, 2016, p. 549). Pouco depois, contudo, Beckett acabou cedendo à insistência de Müller-Freienfells, que Ihe garantiu que todos os esforços seriam feitos para levar a produção a bom termo, e, talvez porque a pré-produção já estava avançada, concordou em retornar a Stuttgart no início de junho daquele ano ${ }^{4}$

Em carta a Jim Lewis de 15 de maio de 1981, Beckett aceita substituir os refletores coloridos pela iluminação uniforme ${ }^{5}$ e, logo no início da produção, em Stuttgart, também concede que os músicos poderiam apenas acompanhar as figuras, agora desempenhadas por pantomímicos no lugar dos dançarinos. A sincronização de um mesmo ritmo básico entre músico e pantomímico foi obtida com o auxílio de um metrônomo, mas as sequências de passos só se tornaram sincrônicas e uniformes com a utilização de fones de ouvido sem fio, de modo que os dançarinos escutassem o metrônomo no ouvido direito e a sua respectiva percussão no esquerdo. As gravações começaram no terceiro dia de trabalho, quando o quadrado, que no início era branco, já tinha se escurecido com os rastros das lixas grudadas nos sapatos. É digna de nota a observação de Körte de que as primeiras gravações da manhã, com todos descansados, eram as menos exatas (mímicos) e diferenciadas (músicos). As melhores só surgiam mais tarde, perto do meio-dia. O perfeccionismo da equipe, determinada à perfeição ou à desistência, permitiu que se chegasse não apenas à precisão de passos e instrumentos, com a introdução de uma pausa da percussão numa das séries, mas também à disponibilidade para a realização da maior novidade da fase de produção em relação ao texto original, a saber, uma segunda versão da peça, Quadrat II, Durante uma conversa, Müller-Freienfells contou a Beckett que havia ficado surpreendido

4 Graley Harren menciona ainda outras cartas em que Beckett se queixa das dificuldades com a produção da peça (HARREN, 2007, p. 123-4).

5 Cf. carta de Beckett a Jim Lewis de 15 de maio de 1981 (FEHSENFELD et al, 2016, p. 550-1): "My feeling at present about mingling and unmingling of coloured light is that we should perhaps drop it altogether and make do with constant neutral light on maximally luminous figures. By reducing the square só as to bring them closer together and accelerating tempo an impression of mingled light and colour could be given while these remain separate. And the withdrawal difficulty removed. The problem then would bem how to get the costumes to shine. Light perhaps no longer from above but circumambient". 
ao ver uma prova num monitor em preto e branco, o que levou um amigo presente, Roman Brodmann, a sugerir que a peça fosse transmitida uma vez em cores e outra em preto e branco. O entusiasmo de Beckett com a ideia levou à produção de uma variação da peça, mais curta e em preto e branco, limitada a uma única série, sem percussão, com figurinos acinzentados e movimentos bem mais lentos. Entre a exibição das duas, disse Beckett, deveria haver um curto intervalo como se entre uma e outra dez mil anos tivessem se passado.

Quadrat I resultou em uma peça mais curta que a versão prevista no texto: apenas oito minutos e meio com início e fim abruptos, sugerindo que a peça mesma é apenas um recorte de um transcurso infinito para além das fronteiras demarcadas pela produção. $A$ versão publicada traz, além de algumas notas acrescentadas após a produção de Stuttgart, um segundo diagrama detalhando como as figuras contornam o centro do quadrado, denominado no texto de "zona de perigo" e referido a Müller-Freienfells como um "abismo". Enquanto os percursos ocorrem em sentido anti-horário, o desvio do centro é feito em sent ido horário.

A B

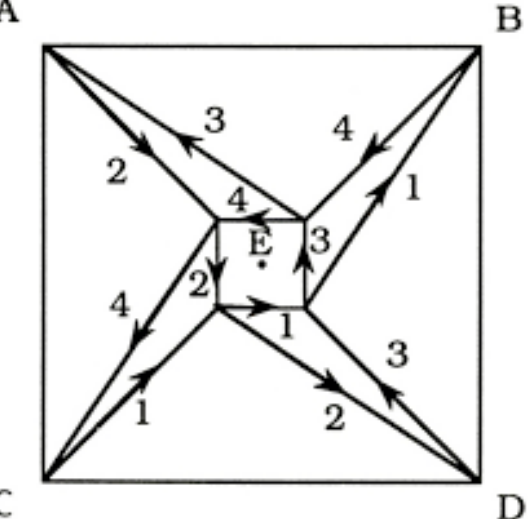

A simetria e a regularidade dos percursos nas quatro séries sugerem um mecanismo funcionando à perfeição, executado por figuras mais próximas de máquinas que de seres humanos. A peça não indica quem está em cena ou por que as figuras se movem; ela limitase a expor sua coordenação com o mecanismo serial, ou seja, ao controle extremo do tempo e do movimento que impede o choque entre elas. É um movimento sem finalidade ou sentido, dest inado a repetir-se infinitamente, sem resolução, como um jogo sem propósito pré-determinado. 


\section{Figuras}

Não é difícil encontrar na obra tardia de Beckett figuras que guardam algumas semelhanças com as de Quadrat I+II. Em seu movimento contínuo e repetitivo, elas se aproximam dos habitantes do cilindro de $O$ despovoador, também condenados a caminhar eternamente em círculos, no mesmo sentido anti-horário das figuras de Quadrat I+/l (e de Dante e Virgílio no Inferno de Dante) em busca do seu despovoador ou de uma saída possível do cilindro. "Recinto onde corpos vão buscando cada um seu despovoador. Amplo o bastante para permitir buscar em vão. Estreito o bastante para que qualquer fuga seja vã" (BECKETT, 2008, p. 5). ${ }^{6}$ Sob o aspecto exterior, com exceção do capuz que cobre as cabeças, as figuras de Quadrat I+l/ também se assemelham aos vultos curvados dos dramatículos tardios, como a figura de May, esculpida em luz na encenação de Beckett para Passos $^{7}$, os duplos de Improviso de Ohio, cujos rostos são parcialmente cobertos pelos cabelos longos ou então, no âmbito das peças televisivas, a figuras também vestidas até os pés com um longo manto, como o personagem de Trio-Fantasma. Apesar da aparente semelhança, também é necessário notar que todos esses exemplos ainda são personagens com vestígios biográficos e lembranças passadas que tomam parte na movimentação em cena: sua const ituição como personagens pode ser lida nos gestos de leitura de um livro (Improviso de Ohio), no ir e vir pelo palco (Passos), ou na sondagem do cômodo fechado enquanto se espera pela visita de alguém que não aparece (Trio-Fantasma). Mesmo em $O$ despovoador, texto em que traços individualizadores como esses não aparecem, o leitor sabe desde o início que os seres do cilindro se movem em busca de algo, quando não de uma saída. Stanley Gontarski assinalou que narrativas como essa se inscrevem num movimento mais amplo da obra tardia de trocar as errâncias dos personagens da obra anterior, de Belaqua e Murphy, passando por Watt, pelos personagens das Três novelas, até Molloy e Malone, pela sondagem dos espaços fechados (GONTARSKI, 2011, p. vii). Como confessa o narrador logo

6 A referência ao movimento anti-horário no Inferno de Dante é constante nos comentários à peça (Mary Bryden, Martha Fehsenfeld, Enoch Brater, Stanley Gontarski). Jonathan Bignell faz um breve sumário dessas posições (BIGNELL, 2009, p. 98). Uma revisão mais extensa da bibliografia secundária encontra-se em HARREN, 2007, 133-6. Baseado na carta a Kaum e nos diálogos com Duthuit, ele arrisca uma interpretação da peça a partir do ideal da tela em branco, do nada a expressar etc. etc. (HARREN, 2007, p. 137-8).

7 A semelhança foi notada por Enoch Brater: "Each figure holds himself in the same posture Billie Whitelaw used in Footfalls, their bodies bent forward as if 'resisting cold wind'. The square itself is a dim area lit 'from above fading out into dark' (...)" (BRATER, 1987, p. 108). 
no início de All Strange Away (e talvez o próprio autor a respeito de sua ficção): "Out of the door and down the road in the old hat and coat like after the war, no, not that again" (BECKETT, 2006, p. 349). Nos trabalhos tardios, a sondagem do espaço fechado vincula-se a formas diversas de auto-questionamento da voz narrativa, como é o caso da segunda trilogia introduzida por Gontarski (Companhia, Mal visto mal dito, Para frente o pior!). 0 despovoador destoa de muitos desses textos tanto pelo distanciamento proporcionado pela voz narrativa em terceira pessoa quanto por configurar uma espécie de errância em espaço fechado. O mesmo se pode dizer de Quadrat $I+I I$, embora nesse últ imo haja ainda menos pistas a respeito dos percursos em cena: nenhum vislumbre de experiência passada ou meta a ser alcançada, nenhuma manifestação de uma voz em off ou de um narrador em terceira pessoa. A designação mesma das figuras como personagens é um problema na medida que a câmera restringe-se à apreensão pela câmera fixa do aspecto exclusivamente exterior dos corpos em movimento serial.

O caráter fortemente mecânico dessa cenografia faz lembrar que formas de atuação à margem de preceitos realistas ou naturalistas não são novidade no teatro beckett iano. ${ }^{8} \mathrm{~A}$ tradição dos clowns e das comédias de vaudeville é incorporada aos personagens das primeiras peças, como Vladimir e Estragon em Esperando Godot e Clov em Fim de Partida. O trabalho de direção desta última para o Schiller Theater de Berlim é um modelo da subst ituição de formas convencionais de atuação pelo embate com os recursos cênicos. Os Atos sem Palavras demostram a familiaridade de Beckett com mímicos, pantomímicos e formas de atuação marcadas por uma forte fisicalidade. Em peças finais como Passos, por sua vez, o caráter fortemente imagét ico da cena contribui para a desmaterialização mesma da personagem que, segundo o próprio Beckett, está e não está lá. Gestos e movimentos dependem tanto ou mais das condições técnicas de encenação - da interação entre corpo e material cênico - do que de motivações internas. Daí a perplexidade de muitos atores com a direção de Beckett, fortemente contrária a qualquer "atuação". ${ }^{9}$

8 A exigência por Beckett de "alguma experiência da dança" para Quadrat é tomada por Deleuze como um ensejo para listar "concordâncias" da obra de Beckett com o balé moderno: "o abandono do privilégio da estatura vertical; a aglutinação dos corpos para se manterem em pé; a substituição das extensões qualificadas por um espaço qualquer; a substituição de toda história ou narração por um "gestus" como lógica das posturas e posições; a busca de um minimalismo; a apropriação, pela dança, da caminhada e de seus acidentes; a conquista de dissonâncias gestuais..." (DELEUZE, 2010, p. 90-1).

9 Bons exemplos disso podem ser encontrados nas entrevistas de Billie Whitelaw e David Warrilow feitas por Jonathan Kalb. Cf. KALB, 1989. Harren também comenta tais entrevistas, além de outras com Pierre Chabert, MacGowran e Schneider (HARREN, 2007, p. 127-130). 
Certas pesquisas sobre o teatro europeu do século $X X$ buscaram inserir posições como essas numa tradição moderna denominada de anti-teatral. É caso do trabalho de Mart in Puchner ao assinalar uma resistência à "teatralidade" compartilhada por diversos encenadores, escritores e dramaturgos (Mallarmé, Yeats, Joyce, Gordon Craig, Gertrude Stein, Brecht, Beckett), teatralidade essa entendida como uma forma de representação ilusionista que teria seu apogeu na obra de arte total wagneriana (PUCHNER, 2002, p. 18). Nessa tradição moderna, sustenta Puchner, os mais diversos recursos cênicos são mobilizados contra a teatralidade: a simbolização de gestos e palavras no teatro simbolista de Yeats e Mallarmé, a separação de elementos e o efeito de estranhamento no teatro épico, a substituição de atores por máquinas e marionetes em Gordon Craig, assim como a disjunção entre gesto e palavra nas peças de Beckett para o teatro e para o rádio. Desse panorama tão diverso é possível destacar um elemento específico que pode ser útil à análise de Quadrat I+II: a marionete. O próprio Beckett a menciona ao referir-se retrospect ivamente a Quadrat I+/l em uma carta a Müller-Freienfels de $1^{\circ}$ de janeiro de 1984 a respeito da produção de $O$ que Onde para a SDR.

As performers I would again suggest mimes. All four to be made so alike as possible by means of costume and make-up however excessive. Attitudes and movement strictly identical. Speech machanical and colourless. Marionettes. No 'interpretation'. A ballet istic approach. Bodily control the most important requirement as in Quad and Nacht und Träume. In a word a discipline and selflessness hardly to be expected of 'seasoned' actors and indeed too much - or too little - to be asked of them (FEHSENFELD et al., 2016, p. 631-2). ${ }^{\text {s }}$

Não cabe aqui examinar como $O$ que Onde retoma procedimentos de Quadrat. 0 importante é notar que Beckett associa controle corporal, disciplina e desprendimento de si (selflessless - abnegação) a um terreno estranho ao da "interpretação", da expressividade convencional, na direção da dança e da mímica, de modo que os atores atuem, mecanicamente, como marionetes. Sendo assim, a atuação se daria no domínio da exterioridade, na conexão entre corpo e máquina, por oposição à exteriorização de uma interioridade psicológica que confira sentido aos movimentos em cena. Não há dúvida de que aqui se encontra uma crít ica à atuação convencional, de feit io psicológico e naturalista. Caberia, contudo, verificar se Beckett endossaria a rejeição mesma à presença do ator no 
palco, compartilhando assim da posição assumida por autores tão distintos como Heinrich von Kleist, que elogia a graça superior dos bonecos em detrimento dos dançarinos, e Edward Gordon Craig, que pretendia expulsar o ator do teatro para dar lugar às máquinas.

Kleist

Que Beckett conhecia e tinha alto apreço pelo ensaio de Kleist, "Do teatro das marionetes", é algo documentado. Ao menos uma vez ele referiu-se ao texto, durante a produção de Trio-Fantasma na BBC, ao discut ir os gestos e a movimentação do personagem pelo cômodo fechado (KNOWLSON, PILLING, 1979, p. 277). O eixo do ensaio de Kleist é a graça superior dos movimentos das marionetes quando comparados aos de um dançarino. Para exemplificá-la, Kleist inicialmente compara o corpo do dançarino, que oferece resistência a seus movimentos, com a força que sustenta e impele a marionete na direção contrária à do solo.

Eles [os bonecos] não são prejudicados pela inércia da matéria, a qualidade mais resistente à dança, pois o poder que os alça para cima é maior que aquele que os mantém no solo. (...) Os bonecos só precisam do solo para tocá-lo e reanimar o balanço de seus membros ao retardar a ação deles por um instante. Nós precisamos do solo para nos recuperar do esforço de dançar, um momento que não é dança, e com o qual não podemos fazer nada além de mostrá-lo tão pouco quanto possível" (KLEIST, 2005, p. 559-60).

Sem prejuízo dessa diferença, o que de fato determina a desvantagem do dançarino é a consciência de seus movimentos. Por oposição à graça, um conceito que Kleist possivelmente toma emprestado de Schiller, a autoconsciência implica cisão, uma distinção entre sujeito e objeto no próprio homem, que determina que ele veja a si mesmo como um outro. A não-consciência da marionete, por outro lado, confere harmonia, simetria e graça aos seus movimentos. A naturalidade dos gestos é avessa à consciência, como se o advento dessa equivalesse à queda ou à separação entre homem e natureza. Kleist ressalva, porém, que gestos humanos realizados sem consciência dos mesmos compartilham da mesma graça das marionetes, o que ele ilustra com a anedota do jovem que, encantado com o próprio movimento involuntário, tenta realizá-lo novamente, sem atingir, contudo, a mesma graça alcançada pouco antes. Os movimentos são marcados por desunião, 
fragmentação e desarmonia.

Nós vemos que à medida que, no mundo orgânico, a reflexão se torna mais fraca e sombria, a graça adentra esse mundo de modo mais reluzente e dominante. Mas assim como a intersecção de duas linhas, de um lado de um ponto, retorna subitamente ao outro lado após passar pelo infinito; ou então como a imagem de um espelho côncavo que depois de mover-se em direção ao infinito subitamente reaparece, também a graça retorna quando o conhecimento se distancia em direção ao infinito. Isso de tal modo que, ao mesmo tempo, ela reaparece de modo mais puro naquela constituição corporal humana que não tem consciência alguma ou então tem uma consciência infinita, ou seja, em uma marionete ou em um Deus. Portanto, eu disse um pouco distraído, deveríamos comer de novo da árvore do conhecimento para recair no estado de inocência? De fato, ele respondeu, esse é o últ imo capítulo da história do mundo (KLEIST, 2005, p. 562).

Ao comentar a recepção desse ensaio por Beckett, Knowlson e Pilling sustentam que as conclusões de Kleist apontam para um estado de graça em que o conhecimento seria total e indivisível, um conhecimento divino em que haveria união entre Deus e natureza. Apesar da distância considerável entre Beckett e tais pressupostos, eles chamam a atenção para dois pontos de contato entre os movimentos da personagem de Trio Fantasma e a marionete de Kleist. Primeiro, o personagem se comporta como se de fato fosse um boneco, seja ao inclinar a cabeça quando julga ouvir a mulher que ele aguarda, seja ao reagir à voz em off, a qual poderia ser interpretada como antecipação ou direção de seus movimentos pelo cômodo. Segundo, a lentidão e a economia dos movimentos contribuiria para a graciosidade dos movimentos, a qual seria ainda mais enfatizada pela direção de Beckett na SDR. Ao tornar os movimentos mais lentos, ele fortaleceria tais qualidades nos menores gestos, de modo que o personagem, ao fazer o que quer ou o que é guiado a fazer, conserva algo daquela inteireza própria ao movimento não-consciente das marionetes.

Knowlson e Pilling ident ificam uma gestualidade semelhante a de Trio Fantasma em outros recônditos da produção teatral beckettiana. A economia de gestos e movimentos num âmbito rarefeito, em que os personagens são ocasionalmente extraídos do seu entorno material, seja como figura espectral, seja como parte de uma natureza morta, também marca a movimentação de May em Passos, que tem no ruído de seus próprios passos um 
vínculo subsistente com o mundo das coisas. É uma forma de atuação atenta ao ritmo musical, aos ecos e às repetições de gestos e falas, algo que Knowlson e Pilling julgam encontrar também em encenações feitas por Beckett de peças anteriores como Dias Felizes e A últ ima gravação de Krapp. São gestos que associam o mínimo ao mecanizado: os atores seguem as instruções precisas do diretor, sem compreender por inteiro a personagem e o que fazem, expondo desse modo a disjunção estabelecida entre interioridade e exterioridade, entre consciência e movimento.

\section{Craig}

Essa forma de atuação não naturalista e mecanizada, própria às marionetes, também está presente em outro texto canônico a respeito do tema, o ensaio de Gordon Craig "O ator e a supermarionete". Embora, salvo engano, não haja registros de que Beckett o conhecesse, o ensaio de Craig fornece um contraponto frutífero para delinear a especificidade da referência de Beckett à marionete. Não há exagero em ler o ensaio de Craig como uma verdadeira cruzada contra o ator no curso da qual os argumentos mais extravagantes são mobilizados para expulsá-lo do palco e substitui-lo por aquilo que ele chama, na falta de uma denominação melhor, de supermarionete. Em linhas gerais, sua condenação do ator deriva de um entendimento mais amplo da arte como atuação consciente e dependente da vontade sobre um material que deve ser submetido a controle absoluto. O problema do ator reside justamente em seu material, o corpo, que resiste ao controle absoluto da mente. À luz de uma rígida dicotomia metafísica entre corpo e mente, tudo o que diz respeito ao corpo - movimentos, gestos, expressões, sons - é de natureza acidental e oscila ao sabor das emoções.

a mente do ator é menos potente que sua emoção, pois a emoção é capaz de subjugar a mente para ajudá-la na destruição daquilo que a mente produziria. E como a mente se encontra escravizada pela emoção, a consequência é que acidentes sobre acidentes continuam ocorrendo. Logo, chegamos a esta conclusão: que a emoção é, a princípio, a causa que cria e que, em seguida, destrói. A arte, como dissemos, não pode admit ir o acaso. Por isso, o que o ator nos oferece não é uma obra de arte, é uma série de confissões acidentais (CRAIG, 2012, p. 103). 
Em seu detalhado estudo sobre Craig, Christopher Innes adverte que as palavras de Craig nem sempre devam ser tomadas ao pé da letra, pois, como um inovador, ele exagerava suas ideias para chamar a atenção do público e dist ingui-las da ortodoxia corrente (INNES, 1983, p. 123). Seu argumento era decerto contra o "ator", mas não contra a performance humana em geral. Na realidade, sua crítica se dirigia contra a performance convencionalizada na passagem para o século $X X$, dominada pela empatia e pelo transporte de forças psicológicas, e que fazia da atuação uma espécie de veículo para a personalidade do ator.

A crítica de Craig almeja, na realidade, um novo teatro avesso à representação corriqueira da realidade cotidiana Não por acaso a condenação metafísica do caráter incontrolável do corpo e das emoções é acompanhada por um diagnóstico histórico do teatro da era moderna, o qual teria se reduzido à imitação servil da natureza. "O ator olha para a vida como uma máquina fotográfica ol ha para a vida, e o que ele busca é fazer uma imagem que rivalize com a fotografia" (CRAIG, 2012, p. 106). No que diz respeito à atuação, a imitação tende à ident ificação plena entre ator e personagem, de modo sugerir ao público que o ator converteu-se por inteiro em Hamlet ou Ricardo III, por exemplo. Como o material da imitação é o corpo incontrolável, a imitação mesma sai prejudicada, cedendo lugar à manifestação da personalidade e dos sentimentos do ator. Reduzida a um realismo empobrecido, a imitação fica aquém da tarefa artística de ir além da natureza.

Eu penso que meu objetivo deveria ser acima de tudo capturar algum relance longínquo deste espírito que chamamos Morte, e resgatar as coisas belas do mundo imaginário. (...) observando-se atentamente a vida, pode-se logicamente pensar que tudo isso trata não do que é belo, nem do que é misterioso, nem do que é trágico, mas do estúpido, do melodramático e do tolo: uma conspiração contra a vitalidade, tanto quanto contra o entusiasmo e a paixão. E dessas coisas que carecem da luz da vida não é possível retirar inspiração. Mas dessa misteriosa, feliz e estupendamente completa vida que é chamada de Morte, essa vida de sombras e de formas desconhecidas, onde não pode tudo ser escuridão e névoa como se supõe, mas de uma cor vívida, uma luz vívida, de formas bem definidas; e onde se encontram pessoas de estranha figura, ferozes e solenes, figuras belas e figuras calmas. (...) A part ir dessa ideia de Morte, que se assemelha a uma primavera, um florescer, desse território e dessa ideia, pode advir uma inspiração tão vasta que, exultante e sem hesitar, eu saltaria em direção a ela, e eis que, em um instante, eu encontraria meus braços 
repletos de flores (CRAIG, 2012, p. 112-3).

A recusa da natureza como fonte de inspiração, assim como do corpo por ser material incontrolável, do qual só se pude extrair resultados fortuitos, abre caminho a Craig para buscar no domínio do inorgânico, ou melhor, do mecânico um modo de rest ituir ao teatro a capacidade de alcançar esse âmbito do imaginário que ele situa para além da vida tal como dada. É nesse contexto que a supermarionete surge como única capaz daquele modo de atuação julgado perfeito por Craig: o estado de "perfeição mecânica", em que o corpo é completamente escravo da mente: "a supermarionete não competirá com a vida, ela irá além dela. Seu ideal não será a carne e o osso, mas o corpo em êxtase. Ele buscará se vest ir com uma beleza mortuária e ao mesmo tempo exalar um espírito vivo" (CRAIG, 2012, p. 118).

O preconceito corrente contra a marionete, que a reduz a um boneco risível, é consequentemente interpretado por Craig não apenas como um reflexo da baixeza do público, mas também como um estágio da decadência da própria marionete. Seu objetivo, portanto, é fazer do teatro o âmbito capaz de restituir à marionete a grandeza e a função que ela teve em tempos imemoriais. É assim que ele julga legítimo rastrear a sua história em templos antigos, na arte asiática e egípcia, em que a marionete aparecia como uma imagem mediadora entre o mundo dado e o domínio das sombras e do imaginário:

A marionete é uma descendente das imagens de pedra de antigos templos. Hoje ela é a forma degenerada de um deus. (...) A marionete me parece o último eco de alguma arte nobre e bela de uma civilização antiga. Mas, como todas as artes, acabou caindo em mãos grosseiras ou incultas e o boneco, a marionete, se tornou uma vergonha. Todos os bonecos atualmente não passam de comediantes vulgares (...) precisamos estudar para refazer estas imagens, não mais simplesmente bonecos, precisamos criar uma Supermarionete (CRAIG, 2012, p. 117-8).

Essa apologia da supermarionete inscreve-se no esforço de Craig em buscar em tradições orientais, como o Teatro Nô, a dança indiana e os bonecos javaneses, assim como na Grécia antiga, elementos para seu projeto de um novo teatro. É em formas mais primitivas, que para ele são também as mais simples, que ele encontra gestos altamente 
estilizados, de caráter simbólico, inscritos uma concepção religiosa e ritualística de espetáculo. Nesse contexto, o espiritual e o transcendente podem ser associados à artificialidade e à simbolização abstrata de estados emocionais própria a bonecos mecânicos e máscaras. O comentário de Innes sustenta, porém, que as marionetes são mais um indicat ivo desse novo teatro do que uma de suas formas concretas e realizadas:

Apesar da reivindicação de que o palco de bonecos possuía "todos os elementos necessários a uma arte bela e criativa", salvo talvez por uma exceção, seus próprios dramas de bonecos não eram mais que peças paródicas, mais um escape para a sua frustração do que material para uma nova forma dramática. Seu verdadeiro objet ivo era criar um equivalente ocidental aos atores altamente treinados do drama Nô, o qual, segundo sua visão, exemplificava as mesmas qualidades intrínsecas do teatro da Grécia antiga: "o [drama-dança] japonês com seu ritual estrito, seu nobre conservadorismo que ainda preserva posturas tradicionais sem mudança ou modificação, sua obediência a uma bela tradição, o perfeito controle de seu material - ou seja, do corpo humano - se aproxima mais de perto das cerimônias esplêndidas e imponentes do passado, das quais, entre nós, alguns traços ainda perduram nos gestos dos padres celebrando a missa, e assim compart il ham de modo mais próximo da natureza de uma arte" (Apud INNES, 1983, 126). ${ }^{10}$

Neste projeto teatral, a marionete é uma orientação do espetáculo pelo ritual. Daí também decorre um novo papel para o artista, distinto do imitador da realidade. Tal como a marionete, o artista vislumbrado (ou corporificado) por Craig deve ser uma espécie de figura sacerdotal. Ao invés de exteriorizar sua personalidade, seus sentimentos, suas paixões e confissões, ele aponta para além da natureza, sendo alguém "que percebe mais que seus colegas, e que registra mais do que aquilo que pode ser visto. E não em menor nível entre os art istas se encontra aquele art ista cerimonial, o criador de visões, o sacerdote cujo dever é celebrar seu espírito orientador, o espírito do Movimento" (CRAIG, 2012, p. 119).

Se o apreço de Craig pela marionete se inscreve numa crítica a um teatro de feitio realista ou naturalista, em que a mímesis é entendida como reprodução verossímil da

10 O trecho citado de Craig é de um texto publicado no primeiro volume de The Mask, a revista editada por ele a partir de 1908. 
realidade, uma tendência que pode ser chamada, com Puchner, de anti-teatral e antiilusionista, então Craig e Beckett transitam por terrenos contíguos. Por outro lado, o forte dualismo de corpo e alma, a aproximação entre a marionete e ídolos e totens da antiguidade, assim como a consequente transformação do teatro num templo, o espetáculo numa cerimônia ritualística e o artista num intermediário do domínio do nãosensível, seja ele o domínio das sombras, do imaginário ou da morte, todos esses fatores afastam Beckett do elogio das marionetes empreendido por Craig. A diferença entre ambos não deixa de ser significativa e, por contraste, é possível notar quão pouco plausível seria afirmar que os movimentos mecânicos e repetitivos de figuras como as de Quadrat I+II remetam a um domínio para além da materialidade mesma dos meios empregados em sua produção.

\section{Séries}

Uma análise mais detida do funcionamento serial pode evidenciar o mecanismo interno que a peça tende a explicitar em seu transcurso temporal. Vimos acima que a estrutura básica concebida por Beckett apresenta quatro séries, cada uma delas iniciada por uma figura a partir de um dos quatro vértices do quadrado. As figuras percorrem trajetos que, na forma de dois triângulos espelhados, passam em sent ido anti-horário pelos quatro lados e pelas duas diagonais internas do quadrado. A sequência das séries corresponde, por sua vez, à apresentação das combinatórias de trajetos possíveis segundo as coordenadas daquele espaço. A delimitação temporal da peça coincide com a apresentação das quatro séries.

Para testar o funcionamento desse esquema, bastaria considerar o que ocorreria se uma das figuras, a primeira, por exemplo, introduzisse variações em seu trajeto, percorrendo a metade oposta ao ponto de entrada (DBCD) antes da primeira metade $(A B C A)$ ou variando a ordem dos lados em cada uma das metades (DBCD, DCBD, assim como $A B C A$ e $A C B A$ ). O resultado seria um choque com as demais figuras em cena, o que impediria o transcurso temporal das demais séries. A variação de um trajeto implicaria, portanto, a alteração correspondente em todos os demais trajetos e, assim, um outro ciclo de quatro séries, distinto desse, em sentido horário, por exemplo. Em outras palavras, qualquer alteração da ordem dos percursos implicaria a destruição da simetria entre as sequências e exigiria uma variação do sistema como um todo. 
Da análise desse mecanismo seria possível afirmar que uma das características do serialismo é o controle do movimento de cada figura pelo movimento das demais. Embora isso se torne visível quando as quatro figuras estão em cena, o mecanismo só é inteiramente explicitado ao fim da quarta série. Em outras palavras, o movimento em cena é determinado pela simetria dos mesmos, seja no interior da série (as figuras saem na mesma ordem em que entraram, realizando quatro percursos) seja no ciclo das quatro séries (cada série é iniciada por uma figura). A sincronicidade dos passos, a equidistância espacial e a manutenção do sentido anti-horário são, portanto, imprescindíveis à execução do ciclo das quatro séries que, ao final, equivale à própria peça. Do ponto de vista da questão das marionetes anteriormente examinada, vê-se que Beckett retoma essa tradição, mas sem postular qualquer hierarquia entre homem e boneco, pois o homem não é substituído pela máquina, mas apresentado por meio da mediação entre seus movimentos físicos e a construção técnica da cena. É a explicitação dessa construção, por sua vez, que organiza a peça como exteriorização do princípio serial que a constitui e ao qual as figuras devem seu movimento em cena, sua relação com o espaço e sua sincronicidade temporal. Forma não é aqui razão ou unidade interna que agrega e transcende as partes ao conferir a elas um sentido orgânico. Nas peças de Beckett, desde Godot, a forma não dispõe mais da necessidade interna dada pela organização teleológica do tempo como ação dramática. Quadrat I+II, contudo, não se vale mais da autoreflexão de teor paródico que marca momentos anteriores do trabalho de Beckett. A forma aqui é dada pela exteriorização de um modo de construir que se efetiva no percorrimento serial do espaço cênico, processo esse que se confunde com a própria peça em seu transcurso temporal.

Essas características do serialismo de Quadrat I+// permitem retomar os dois modos de série lembrados por Steven Connor a respeito de Watt: 1) a permutação finita, que permite a exaustão de todas as combinações e relações possíveis entre elementos de uma dada estrutura. Esse é, segundo Connor, um modo fechado de série, pois chega a termo ao evidenciar plenamente seu funcionamento. Em Watt, a permutação finita caracteriza o raciocínio combinatório do protagonista ao apreender a rot ina da casa de Mr. Knox; 2) além desse modo, Connor discute também o modo aberto de série, que se caracteriza pela sequência de alternativas desdobrável ao infinito. Ela aparece, por exemplo, na remissão de Arsène a seus antepassados e sucessores, dentre os quais o próprio Watt, que o sucede e será um dia sucedido por outro, numa sequência a princípio infinita de empregados de Mr. 
Knox (CONNOR, 1988, p. 30).

É possível encontrar estes dois modos de série em Quadrat I+ll. O percorrimento de quatro percursos em quatro séries indica o cumprimento de um ciclo no interior do quadrado. Com o fim da quarta série, a estrutura se torna plenamente visível, tal como no primeiro modo de funcionamento das séries lembrado por Connor. Em Watt, quando isso ocorre, não é apenas a série que se encerra, mas também um episódio do romance, que passa então a outros desenvolvimentos distintos da explicitação daquela série específica. Não é o que ocorre em Quadrat I+II, em que a exposição do ciclo de quatro séries está dest inada a repetir-se indefinidamente. Certamente é possível questionar se o ciclo seria repetido tal e qual foi apresentado ou então como uma variação do primeiro, em sentido horário, por exemplo, mas a questão permanece em aberto. Se o fim da peça é dado pelo corte abrupto da apresentação do ciclo, nada indica que um outro não comece a seguir. Também é possível dizer que a peça não conclui a apresentação dos trajetos possíveis pelo quadrado, mas apenas abandona o seu registro um ciclo possível de séries. O início, por sua vez, marcado pela saída da figura amarela segundos antes do início das quatro séries pela branca, parece um espelhamento (ou uma antecipação) do final da quarta série, o que indicaria que o ciclo das quatro séries seria a repet ição do ciclo anterior, dest inado a repet irse indefinidamente. Sob esse aspecto, Quadrat I+// também apresenta o segundo tipo de série, a do sequenciamento infinito, com a diferença de que ela não é mais qualitativa, como na série de funcionários do Sr. Knox, mas uma repetição do mesmo.

Se, como indicamos acima, a peça coincide com a exteriorização de seu modo de funcionamento, uma vez completado esse processo, não seria mais necessário continuar. A peça está feita. Quadrat II, contudo, fornece uma dinâmica, ou ao menos uma moldura ao serialismo repet it ivo de Quadrat I. Após um número indefinido de repet ições - dez mil anos segundo Beckett -, a velocidade diminui como resultado do cansaço das figuras, indicando que o mecanismo em algum momento poderá cessar, como um relógio sem corda. O fadeout da segunda peça no lugar do corte repent ino da peça anterior não sugere, por sua vez, um termo ou uma conclusão, mas um processo de lento desaparecimento, de perda de contornos e movimentos até o completo apagamento nas sombras da imagem escurecida. Esse enquadramento insere uma dimensão qualitativa - uma mudança de condição - num transcurso temporal inicialmente quantitativo e repetitivo. O fluxo infinito tende a 
estancar no decurso da repet ição infinita. ${ }^{11}$

Características com essas revelam uma especificidade formal de Quadrat I+ll: um apurado senso de construção formal articulando um transcurso temporal que extravasa os limites da obra. Leitores e espectadores de obras anteriores como O Inominável e Fim de partida sabem que início e fim indetermináveis não const ituíam uma novidade na produção beckettiana, bem como o uso frequente e variado de repetições, séries e combinatórias na prosa e no teatro. ${ }^{12}$ A especificidade de Quadrat I+ll está na coincidência entre o percorrimento das séries e a explicitação da peça como um todo. Nesse sentido, Quadrat I+II se constitui pelo isolamento desse procedimento de todos os elementos de cunho narrativo e dramático que habitavam seus trabalhos em prosa e para o teatro. A tão menciona "desconfiança" de Beckett em relação à linguagem, assim como sua tendência a compor peças cada vez mais imagéticas, desempenham seu papel, mas também é importante notar que ali, no teatro e na prosa, as séries e as repetições eram mecanismos de atrito com vestígios dos gêneros épico e dramáticos que ainda subsistiam na produção beckettiana, seja em registro paródico nos primeiros trabalhos, seja no entrelaçamento posterior de memória, imaginação e fabulação na sondagem da experiência individual em obras dificilmente reconhecíveis no âmbito das convenções de um gênero. Quadrat I+/I partilha do mesmo terreno dessas últ imas obras, em que a especificidade do meio artístico empregado é tão ou mais importante que traços de gênero, mas, num meio recente como a

11 Nesse contexto, também é importante notar que a contraposição entre uma peça em cores e outra em preto e branco dialoga com a própria história da televisão, como bem apontou Jonathan Bignell: "Black and white could represent an earlier time than colour in a television context since that matches the history of the medium, and this would produce an interesting reversal of the assumptions about causal linearity that have governed interpretation so far. What has been interpreted as a vision of a distant future might also be understood as a recapitulation of television drama's past, thus rendering volatile the notions of temporal progression and teleological development within the drama, and its relationships with histories of its medium" (BIGNELL, 2009, p. 99).

12 Em Murphy, romance de estreia, elas aparecem em meio a um roteiro predominantemente linear em dois episódios da vida do protagonista. No romance seguinte, Watt, o enredo é em grande parte uma apresentação das séries e combinatórias possíveis a partir dos poucos elementos que constituem a estadia de Watt na casa do Sr. Knott. Em Molloy, primeiro romance da trilogia, o episódio das pedras de chupar é um outro caso em que o desdobramento da ação rarefeita cede lugar a demostração de um mecanismo serial de motivação inteiramente banal. O mesmo romance também uma estrutura repetitiva por meio do espelhamento das trajetórias de Molloy e Moran, como se a trajetória desse último desembocasse na trajetória do primeiro, conectando assim o fim ao início do romance em uma estrutura repetitiva. O desenvolvimento serial marca ainda o último experimento de Beckett com o gênero do romance, Como é, por meio da relação entre suas três partes: antes de Pim, com Pim e depois de Pim. A sugestão de uma repetição infinita reaparece também no teatro: na simetria dos dois atos de Godot, na repetição dos mesmos episódios rotineiros em Fim de partida, cuja impossibilidade de desfecho é alçada a tema. Em peças tardias, como Rockaby e em trabalho para a televisão como Ghost Trio e ...But the clouds..., a posição da voz em off perante a cena determina o transcurso temporal da peça como uma repetição de tentativas e variações de um mesmo motivo básico. 
TV, sem convenções tradicionais sedimentadas, tornou-se possível realizar o que os outros meios não tinham permit ido - a peça serial.

\section{Bibliografia}

ANDRADE, Fábio de Souza. Samuel Beckett: o silêncio possível. São Paulo: Ateliê, 2001. . "Try again. Fail again. Fail better". In: Beckett, S. O despovoador/Mal Visto Mal Dito. São Paulo, Mart ins Fontes, 2008.

BECKETT, S. The Grove Centenary Editions of Samuel Beckett: Novels I; Novels II; The Dramat ic Works; The Poems, Short Fict ion and Criticism. Nova York: Grove, 2006.

. Quad et autres pièces pour la télevision suivi de L'Épuisé, par Gilles Deleuze. Paris:

Les Édit ions de Minuit, 1992.

Samuel Beckett - Works for radio: the original broadcasts BBC. Londres: The Brit ish Library, 2006 [C.Ds]

Samuel Beckett: Filme für den SDR - He, Joe, Quadrat I und II, Nacht und Träume, Geister-Trio. Filmedition Suhrkamp. Frankfurt am Main: Suhrkamp, 2008 [DVDs\} Samuel Beckett: documents sonores (En attendant Godot/ Oh les beaux jours/Tous ceux qui tombent/Compagnie/ L'expulsé/ Le dépeupleur). Andre Dimanche (Ed.). Bry sur Marne, France: Institut National de l'Audiovisuel, 2007 [Cds]

. O despovoador; Mal visto mal dito. São Paulo, Mart ins Fontes, 2008.

BIGNELL, Jonathan. Beckett on screen. The television plays. Manchester, Manchester University Press, 2009.

BORGES, Gabriela. A poética televisual de Samuel Beckett. S.Paulo: AnnaBlume/Fapesp, 
2009 .

BRATER, Enoch. The drama in the text: Beckett's late fiction. Oxford: Oxford University Press, 1994 .

Beyond minimalism: Beckett's late style in the theater. Nova York: Oxford University Press, 1987.

CONNOR, Steven. Samuel Beckett: repetition, theory and text. Cambridge, Cambridge University Press, 1988.

CRAIG, Edward Gordon. "O ator e a supermarionete", in Sala Preta, vol. 12, n. 1, junho 2012.

DELEUZE, Gilles. Sobre o teatro: Um manifesto de menos. O esgotado. Rio de Janeiro, Zahar, 2010.

FEHSENFELD, M. e OVERBECK, L. CRAIG, G. e GUNN, D. (ed) The letters of Samuel Beckett. Cambridge/Nova York: Cambridge University Press, 2016.

GARDNER, Colin. Beckett, Deleuze and the televisual event. Peephole Art. London, Palgrave Macmillan, 2012.

GATTI, Luciano. "Narração ou teoria? Adorno e O Inominável de Samuel Beckett", in Literatura e Sociedade, no. 17, 2013.

. "Murphy, antes e depois de Beckett", in Novos Estudos CEBRAP, no. 98, março de $2014 a$.

. "Coreography of Disobedience: Beckett's Endgame', in Journal of Beckett Studies 23.2, September 2014b.

. "Adorno e Beckett. Aporias da autonomia do drama", in Kriterion, no. 130, $2014 \mathrm{C}$.

GONTARSKI, S.E. (ed.) On Beckett: essays and criticism. Nova York: Grove, 1986.

. (ed.) The theatrical notebooks of Samuel Beckett: the shorter plays. Londres: Faber \& Faber, 1999.

. "The conjuring of something out of nothing: Samuel Beckett's 'closed space' novels". In BECKETT, Samuel. Nohow On. Three Novels, Grove Press, 2011.

(ed.) The Edinburgh companion to Samuel Beckett and the arts. Edinburgh: E.U.P, 2014 .

GONTARSKI, S. e ACKERLEY, C.J. The Grove companion to Samuel Beckett. Nova York: Grove, 2004 .

HARREN, Graley. Samuel Beckett's plays on film and television. London, Palgrave Macmillan, 2007. 
KÖRTE, Konrad. "Wie es war: Samuel Beckett inszeniert Quadrat I und Quadrat II in Stuttgart", in HARTEL, Gaby. e GLASMEIER, Michael. (eds.) The Eye of Prey: Beckett's Film-, Fernseh- und Videoarbeirten. Berlin: Suhrkamp, 2011.

HICKETHIER, Knut. "Fernsehästhetik. Kunst im Programm oder Programmkunst?". In PAECH, Joachim (Hrsg.). Film, Fernsehen, Video und die Künsten. Strategien der Intermedialität. Stuttgart, Metzler, 1994. . Das Fersehspiel der Bundesrepublik. Stuttgart, Metzler, 1980.

KALB, Jonathan. Beckett in performance. Cambridge: CUP, 1989.

KNOWLSON, James. Damned to Fame. The Life of Samuel Beckett. New York: Grove Press, 1996.

KNOWLSON, James \& PILLING, John. Frescoes of the skull: the later prose and drama of Samuel Beckett. London: John Calder, 1979.

McMULLAN, Anna. Theatre on trial: Samuel Beckett's later drama. London: Routledge, 1993.

MÜLLER-FREIENFELS, Reinhart. "Erinnerungen an Samuel Beckett beim SDR. In:

FÜNFGELD, Hermann (Hrsg.). Von außen besehen Markenzeichen des Süddeutschen Rundfunks. Stuttgart, Süddeutscher Rundfunk, 1998.

PILLING, J. (ed) The Cambridge companion to Samuel Beckett. Cambridge: C.U.P.,1994.

PUCHNER, Martin. Stage Fright. Modernism, Anti-Theatricality and Drama. Baltimore, The John Hopkins University Press, 2002.

SEIBERT, P. (ed.) Samuel Beckett und die Medien. Transcript, 2008.

WULF, Catharina (ed.). The savage eye / L'oeil fauve. New essays on Samuel Beckett's television plays. Amsterdan, Rodopi, 1995.

\footnotetext{
${ }^{\text {i }}$ Professor do Departamento de Filosofia da Unifesp. Autor de Constelações. Crítica e verdade em Benjamin e Adorno (Loyola, 2009) e A peça de aprendizagem. Heiner Müller e o modelo brechtiano (Edusp/Fapesp, 2015). O presente artigo contou com o apoio de uma Bolsa de Produtividade em Pesquisa do CNPq e de uma Bolsa de Estágio Sênior pelo convênio CAPES/Humboldt.
} 